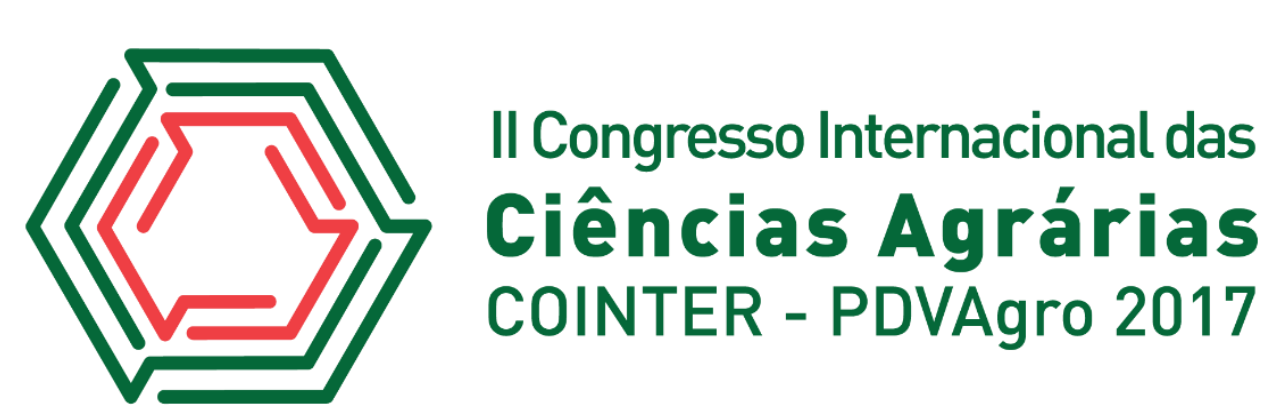

\title{
CONSTRUÇÃO DE CAIXA ENTOMOLÓGICA COMO FERRAMENTA FACILITADORA PARA A APRENDIZAGEM DA DISCIPLINA ENTOMOLOGIA AGRÍCOLA
}

\author{
Apresentação: Relato de Experiência \\ Ayane Lima Ferreira ${ }^{1}$; Maria Roselane Alves Oliveira ${ }^{2}$; Cristiane Nunes da Conceição ${ }^{3}$; Gutierres \\ Nelson da Silva ${ }^{4}$
}

\section{Introdução}

Para Humphrey et al. (1999), os insetos são indivíduos bastante estudados, com o intuito de expandir o conhecimento sobre sua diversidade e também para a estruturação e funcionamento dos ecossistemas terrestres. Portanto coleções entomológicas, ou caixas de insetos são de suma importância para trabalhos de sistemática, taxonomia e biologia dos diversos grupos que compõem a classe Insecta. Nas caixas entomológicas encontram-se armazenados, ordenados e preservados espécimes ou estruturas de espécimes para pesquisas e estudos (PAPAVERO,1983).

Este estudo relata a contribuição da confecção de coleções entomológicas como alternativa didática na disciplina de Entomologia Agrícola, explanando a eficiência dessa abordagem didática na construção do conhecimento dos alunos envolvidos.

\section{Relato de Experiência}

A experiência foi realizada no município de Codó, MA, localizado na mesorregião do Leste Maranhense, no Instituto Federal de Educação, Ciência e Tecnologia do Maranhão, Campus Codó. As atividades de montagem de herbário foram realizadas no primeiro semestre de 2016, na disciplina, entomologia agrícola, ministrada pelo professor Gutierres Nelson da Silva. A atividade foi realizada em duas fases: na primeira, o professor trabalhou a parte teórica, explanando os principais insetos-praga de culturas agrícolas, bem como os inimigos naturais. Já na segunda fase foi proposto uma atividade pratica com a montagem de caixa entomológica. Os insetos foram coletados nas imediações do Campus e em propriedades de pequenos produtores da região.

Exigiu-se para cada caixa entomológica um quantitativo de 20 insetos (15 insetos-praga e 5 inimigos naturais).

\footnotetext{
${ }^{1}$ Agronomia,IFMA, ayaneagro14@gmail.com

${ }^{2}$ Agronomia,IFMA,roselany.alves@hotmail.com

${ }^{3}$ Agronomia,IFMA,cristianenunes2996@gmail.com

${ }^{4}$ Doutor, IFMA, gutierres.silva@ifma.edu.br
} 
Para a construção da caixa entomológica utilizou-se uma caixa de papel de formato retangular, com uma placa de isopor encapado com papel melimetrado com suas devidas etiquetas de identificação dos insetos. Essas etiquetas continham a ordem e nome científico (insetos-praga) e ordem e família (inimigos naturais). Depois de capturados os insetos permaneciam imersos por $24 \mathrm{~h}$ em álcool 70\%, após isto, foram espetados com alfinetes nos locais indicados pela literatura com sua devida identificação. Na caixa entomologia, os insetos foram acondicionados por três formas: 1: as lagartas e insetos minúsculos foram armazenados em eppendorf; 2: as pragas de grãos armazenados foram armazenados em triângulos de papel $(1 \mathrm{~cm})$; 3: os demais insetos foram espetados em alfinetes.

Imagem 1: Atividade Experimental. Fonte: Própria

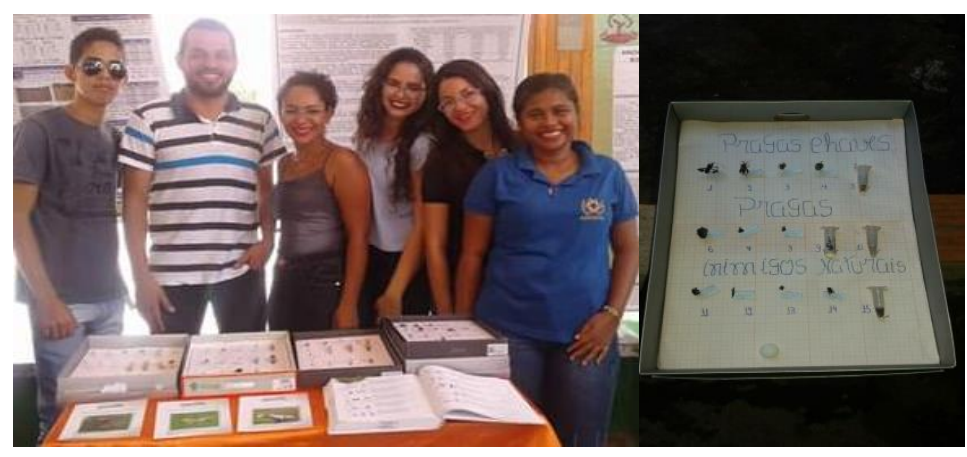

\section{Considerações}

Ao longo da disciplina, pode-se observar que os acadêmicos do $6^{\circ}$ período de agronomia se mostraram motivados para coletar as espécies em campo, demonstrando que a caixa entomológica serviu como uma ferramenta de ensino para identificação correta de espécies de insetos- pragas de importância agronômica. A coleção proporcionou aprendizado dos alunos através do reconhecimento de pragas e inimigos naturais, bem como, características morfológicas de cada inseto. Podemos ainda demonstrar o trabalho em pátio, e convidamos outras escolas para conhecer melhor nossas experiências na disciplina.

\section{Referências}

HUMPHREY, J. W. et al. Relationships between insect diversity and habitat characteristics in plantation forest. Forest Ecology and Management, Amsterdã, n. 1, v. 113, p. 11-21, jan. 1999.

Fundamentos práticos de taxonomia zoológica: coleções, ibliografia, nomenclatura/ Nelson Papavero organizador.- - 2 ed. rev. e ampl. -São Paulo : Editora da Universidade Estadual Paulistana , 1994, -( Natura naturata). 